\title{
Edge-Spread Functions Expected for Several Changes in a Commercial Flat-Panel System
}

\author{
A.E. Schach von Wittenau
}

February 25, 2002

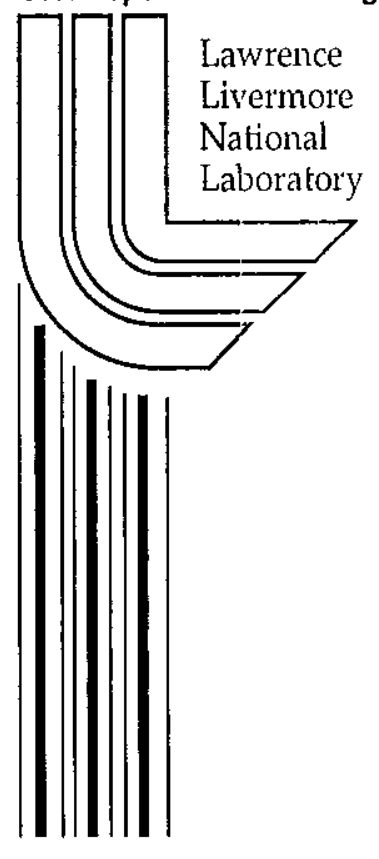




\section{DISCLAIMER}

This document was prepared as an account of work sponsored by an agency of the United States Government. Neither the United States Government nor the University of California nor any of their employees, makes any warranty, express or implied, or assumes any legal liability or responsibility for the accuracy, completeness, or usefulness of any information, apparatus, product, or process disclosed, or represents that its use would not infringe privately owned rights. Reference herein to any specific commercial product, process, or service by trade name, trademark, manufacturer, or otherwise, does not necessarily constitute or imply its endorsement, recommendation, or favoring by the United States Government or the University of California. The views and opinions of authors expressed herein do not necessarily state or reflect those of the United States Government or the University of California, and shall not be used for advertising or product endorsement purposes.

This work was performed under the auspices of the U. S. Department of Energy by the University of California, Lawrence Livermore National Laboratory under Contract No. W-7405-Eng-48.

This report has been reproduced directly from the best available copy.

Available electronically at http://www.doc.gov/bridge

Available for a processing fee to U.S. Department of Energy

And its contractors in paper from

U.S. Department of Energy

Office of Scientific and Technical Information

P.O. Box 62

Oak Ridge, TN 37831-0062

Telephone: (865) 576-8401

Facsimile: (865) 576-5728

E-mail: reports@adonis.osti.gov

Available for the sale to the public from

U.S. Department of Commerce

National Technical Information Service

5285 Port Royal Road

Springfield, VA 22161

Telephone: (800) 553-6847

Facsimile: (703) 605-6900

E-mail: orders@ntis.fedworld.gov

Online ordering: http://www.ntis.gov/ordering.htm

OR

Lawrence Livermore National Laboratory

Technical Information Department's Digital Library

http://www.llnl.gov/tid/Library.html 


\title{
Edge-spread functions expected for several changes in a commercial flat-panel system
}

\author{
A. E. Schach von Wittenau \\ Lawrence Livermore National Laboratory, Livermore, CA 94550
}

(February 25, 2002)

\section{SUMMARY}

The Bldg, 239 radiography facility uses a $9 \mathrm{MeV}$ bremsstrahlung linac and a commercially available flat-panel detector system. Ref. [1] discusses the facility in detail. Ref. [1] furthermore discusses the imaging quality of the flat-panel system, and identifies several sources of image blur for the system in question. The major contributors to the imaging blur are radiation scattered from the front cover of the detector housing, radiation scattered from the back cover of the detector housing, and radiation scattered from the aluminum plate that supports the amorphous-Si detector within the detector housing.

The manufacturer of one such flat-panel system seems willing to modify one of their products as requested, if such modifications may be made easily. Easy modifications would include making the detector housing thinner, decreasing the sizes of air gaps inside the detector system, etc. Removing the aluminum support plate is considered to be a difficult modification.

This memo reports the results of a set of Monte Carlo simulations that were performed to predict the changes in imaging quality, compared to that of the current system, if the detector is modified as suggested above. In particular, the edge-spread function (ESF) was calculated for each modification. ESFs were calculated for three photon energies: $100 \mathrm{keV}, 450 \mathrm{keV}$, and $3 \mathrm{MeV}$.

The results suggest that thinning and moving the front and back covers of the detector housing should result in improved image quality for all of the photon energies considered. Interestingly, the results also suggest that removing the aluminum support plate would improve the imaging performance at $100 \mathrm{keV}$ and $450 \mathrm{keV}$, but that removing the plate has no additional benefit for imaging with $3 \mathrm{MeV}$ photons.

\section{METHODS AND MATERIAIS}

The Monte Carlo simulations were performed using MCNP4C. Dimensions and materials specifications were obtained from the manufacturers of flat panel systems. An MCNP input deck for the current imaging system had already been generated for use in Ref. [1]. Changes to the original deck to reflect the changes discussed here required very little effort.

Six detector configurations were modeled, using the methods described in Ref. [1], and the resulting ESFs are shown in Figs. 1-3. The configurations, along with the mnemonics, are:

1. none: the original configuration;

2. movefront: the front cover has been moved $4 \mathrm{~mm}$ closer to the Lanex screen, thus decreasing the air gap between the front cover and the rest of the system;

3. thinfront: the front cover is thinned to $0.75 \mathrm{~mm}$, but the air gap has the same thickness;

4. thinback: both the aluminum support plate and the back aluminum plate have half their original thickness; the air gap remains unchanged;
5. both: the front cover is moved in, and the two aluminum plates have their thicknesses halved;

6. support: the front cover is moved in, the back plate is thinned, and the aluminum support plate is removed.

Table 2 of Ref. [1] gives a detailed description of the detector system. An abbreviated description of the structural parameters is given in Table I.

Edge-spread functions were calculated for three photon energies: $100 \mathrm{keV}, 450 \mathrm{keV}$, and $3 \mathrm{MeV}$. Results are shown in Figs. 1-3.

\section{RESULTS}

Fig. 1, for $100 \mathrm{keV}$ photons, shows that all of the changes considered should improve the edge-spread function of the detector. In order of increasing improvement in image quality, the configurations are: none, then movefront, then thinfront, then thinback, then both, then support. This ordering suggests that the front cover is a small contributor to image blur, at this photon energy. Removing the aluminum support plate should have a significant effect on the sharpness of the ESF. 
Fig. 2, for $450 \mathrm{keV}$ photons, also shows that all of the changes considered should improve the edge-spread function of the detector. In order of increasing improvement in image quality, the configurations are: none, then movefront, then thinfront, then thinback, then both, then support. This ordering suggests that the front cover is a small contributor to image blur, at this photon energy. The back plates have a significant influence on the image quality, more so than for the $100 \mathrm{keV}$ case. Here, too, removing the aluminum support plate should have a significant effect on the sharpness of the ESF.

The $3 \mathrm{MeV}$ case shows a different pattern. In order of increasing improvement in image quality, the configurations are: none, then thinfront or thinback, then movefront, then support, then both. In this case, adjusting the front cover has a stronger effect than does adjusting the back aluminum plates. This is likely due to the front cover's now being a significant source of scattered radiation. This scattered radiation would be in a forwarddirected cone. Moving the front cover closer to the detector element would decrease the projected area of this cone, thus yielding a narrower ESF. Modifying the down- stream portions of the detector system appears to be less useful.

\section{ACKNOWLEDGMENTS}

This work was performed under the auspices of the U.S. Department of Energy by the University of California, Lawrence Livermore National Laboratory under Contract W-7405-Eng-48.

[1] A. E. Schach von Wittenau, C. M. Logan, M. B. Aufderheide, III, and D. M. Slone, "Blurring artifacts in megavoltage radiography with a flat-panel imaging system: Comparison of Monte Carlo simulations with measurements," submitted to Med. Phys. (2001), UCRL-JC144247. 
TABLE I. Materials, densities, and layer thicknesses used for the MCNP simulations of the notional imaging system.

\begin{tabular}{|c|c|c|c|c|c|c|c|}
\hline \multirow[b]{2}{*}{ Component } & \multirow[b]{2}{*}{ density } & \multicolumn{6}{|c|}{ Component thickness (mm) } \\
\hline & & original & movefront & thinfront & thinback & both & support \\
\hline Carbon fiber front cover & 1.6 & 1.5 & 1.5 & 0.75 & 1.5 & 1.5 & 1.5 \\
\hline air gap & 0.0012 & 6.5 & 2.5 & 6.5 & 6.5 & 2.5 & 2.5 \\
\hline Al support plate & 2.7 & 4.83 & 4.83 & 4.83 & 2.415 & 2.415 & 0.0 \\
\hline air gap & 0.0012 & 20.3 & 20.3 & 20.3 & 20.3 & 20.3 & 22.715 \\
\hline Al back cover & 2.68 & 2.54 & 2.54 & 2.54 & 1.27 & 1.27 & 1.27 \\
\hline
\end{tabular}



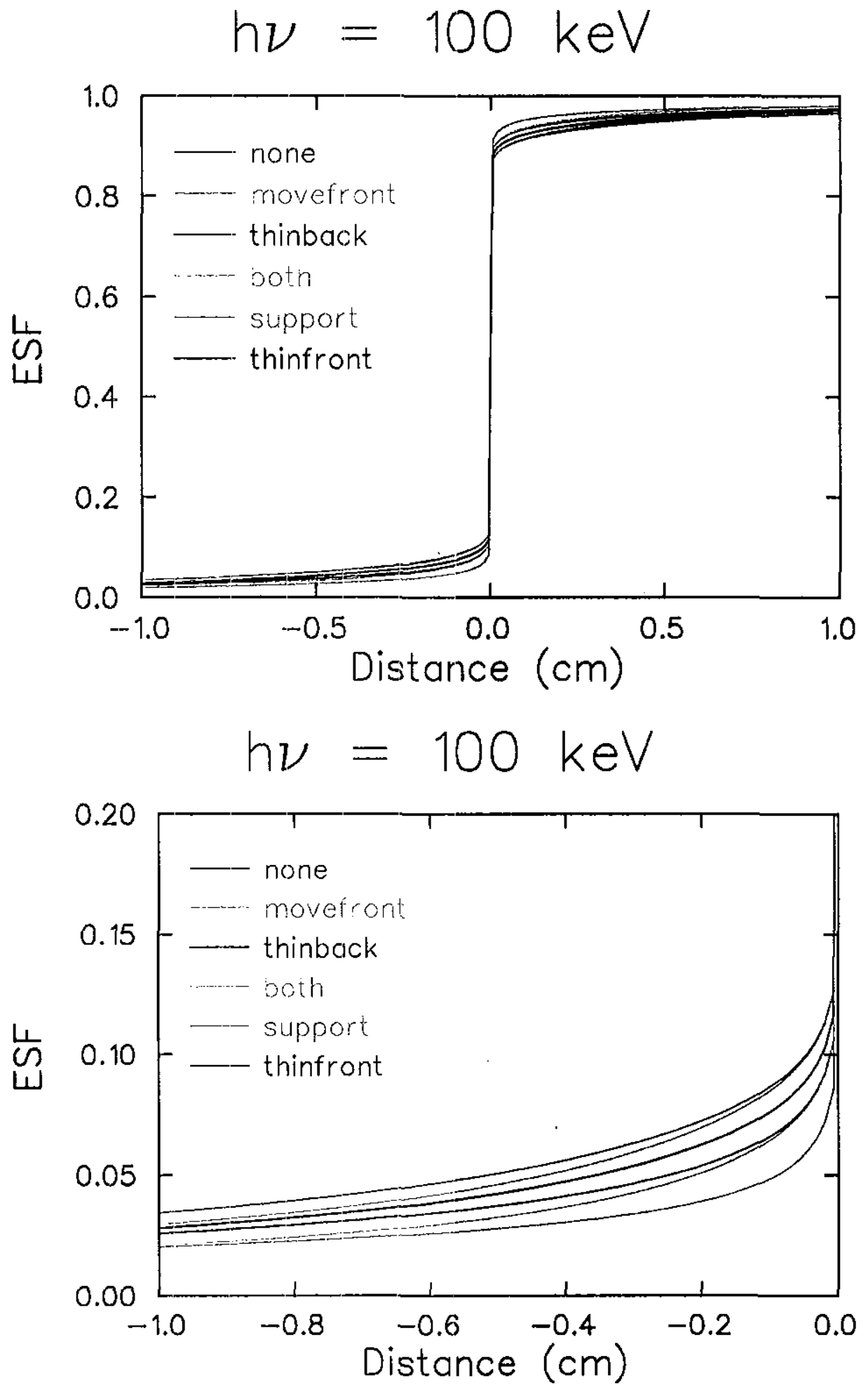

FIG. 1. Edge spread functions for the various cases, assuming a $100 \mathrm{keV}$ monoenergetic beam. 

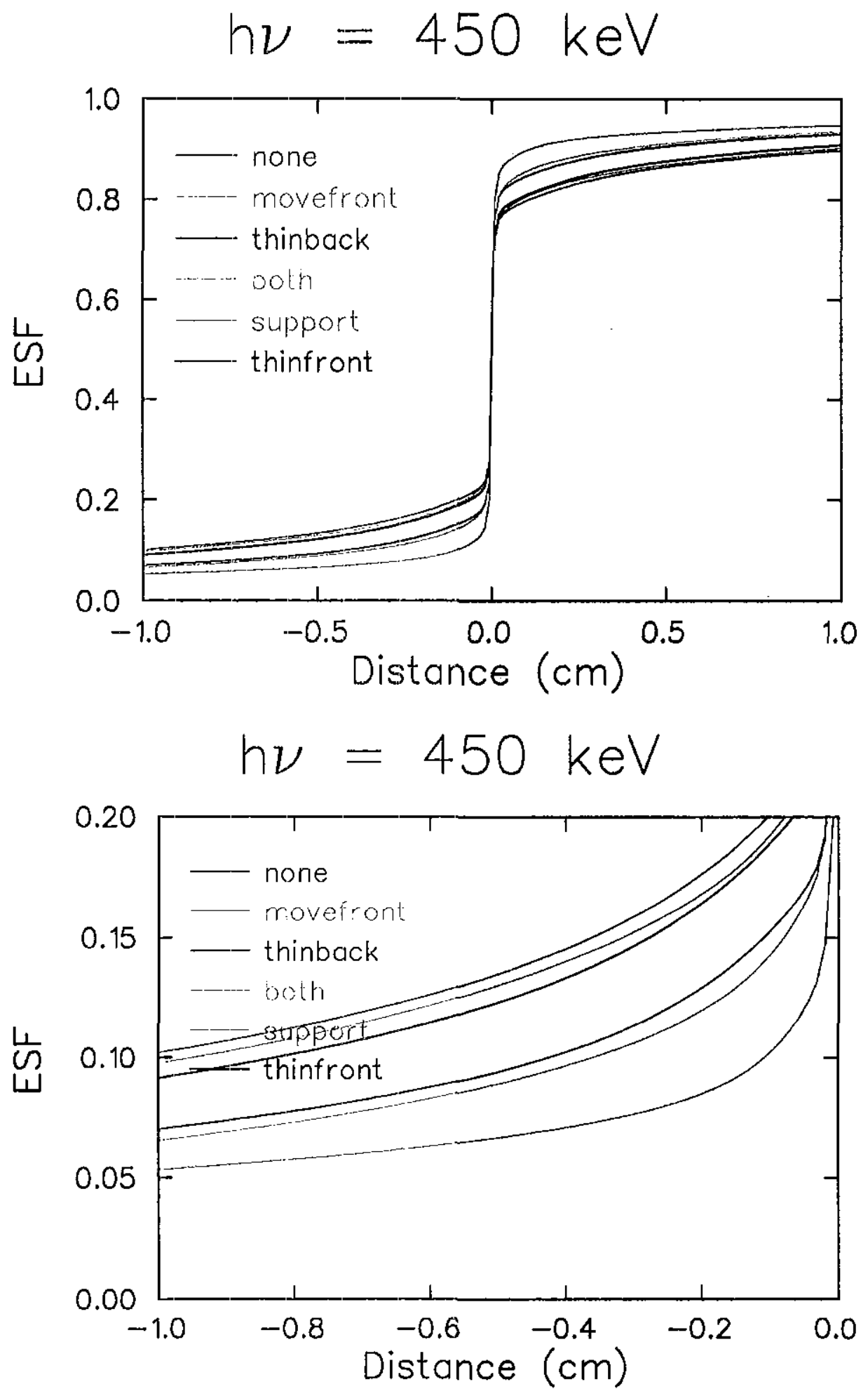

FIG. 2. Edge spread functions for the various cases, assuming a $450 \mathrm{keV}$ monoenergetic beam. 

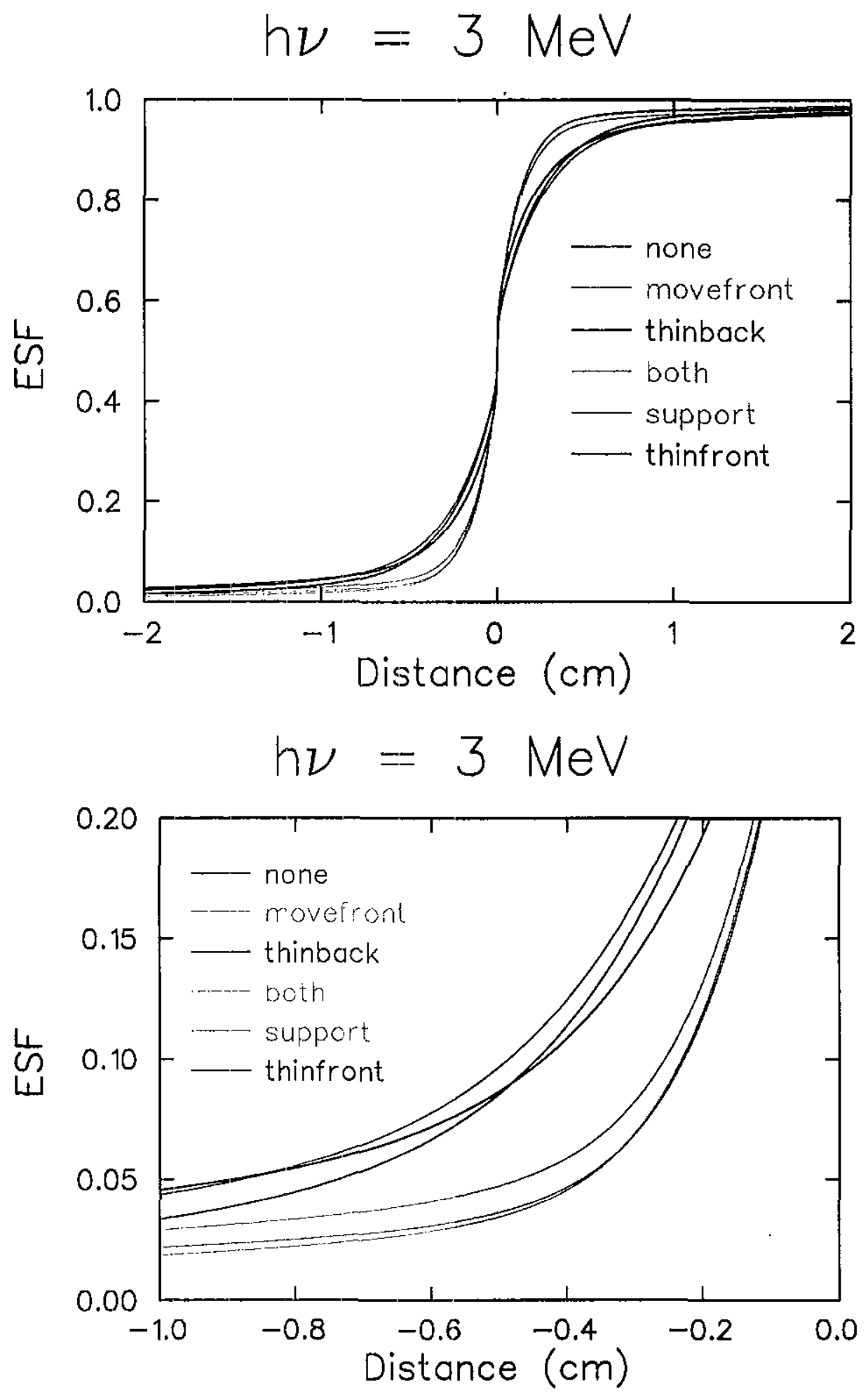

FIG. 3. Edge spread functions for the various cases, assuming a $3 \mathrm{MeV}$ monoenergetic beam. 